Case report

\title{
ACCESSORY SPLEEN IN A DOG: MACROSCOPIC AND MICROSCOPIC FINDINGS
}

\author{
M. N. NAZEM ${ }^{1}$, S. M. SAJJADIAN ${ }^{1}$, R. KHEIRANDISH ${ }^{2}$ \\ \& M. A. SHAMSHIRGARAN ${ }^{3}$ \\ ${ }^{1}$ Department of Basic Sciences, ${ }^{2}$ Department of Pathobiology, ${ }^{3}$ Undergraduate Stu- \\ dent; School of Veterinary Medicine, Shahid Bahonar University of Kerman, Iran
}

\section{Summary}

Nazem, M. N., S. M. Sajjadian, R. Kheirandish \& M. A. Shamshirgaran, 2021. Accessory spleen in a dog: Macroscopic and microscopic findings. Bulg. J. Vet. Med., 24, No 2, 297-302.

\begin{abstract}
Accessory spleens are one or more areas of normal ectopic splenic tissue of variable size supplied by the branches of the splenic artery. A 7 year-old mixed breed male dog was fixed for use as a model in anatomy hall. During the abdominal dissection, the gross examination showed a $6.3 \times 3.1 \times 1 \mathrm{~cm}$ mass that was situated on the caudodorsal border of the spleen. Its appearance and firm consistency were similar to those of spleen. There was no connection between the spleen and this mass. It was supplied by accessory splenic artery. Microscopic examination of the mass revealed some structures similar to spleen.
\end{abstract}

Key words: accessory spleen, dog, histopathology

The spleen is the largest lymphoid organ in the body, situated in the left hypogastric region. Congenital anomalies of the spleen are generally occurring infrequently in animals, and include splenomata, duplications, absence of the spleen (alienia), multiple small spleens, displacements (ectopia), and the presence of one or more accessory spleens (Kurmann et al., 2010).

Accessory spleen is a congenital anomaly that consists of ectopic splenic tissue separated from the main body of the spleen. The spleen develops from the mesenchymal cells that migrate during foetal life into the dorsal mesogastrium and a failure in the fusion of splenic tissue in the formation of an accessory spleen (Fontan et al., 2001). It is frequently asymptomatic. Accessory spleens have been found as an incidental finding in autopsy series and also in $33 \%$ of patients with haematologic diseases (Freeman et al., 1993). Occasionally accessory spleen may appear with symptoms related to acute or recurrent torsion and infarction (Fontan et al., 2001). In humans, about $10 \%$ of the population is reported to have accessory spleens, which are usually located at or 
near the splenic hilum. However, $16 \%$ of accessory spleens are found in the pancreatic tail (Lauder, 1992; Lehtinen et al., 2013). Accessory spleens, when multiple, almost always occur together in a single location. Their sizes vary, but most are about $1 \mathrm{~cm}$ in diameter (Tatekawa, 2018).

Accessory spleens are regarded as the most common splenic anomaly in domeset al., 2010; Adak et al., 2013). There are many reports on the incidence of the accessory spleen in pigs (Swarbrick, 1968), rabbits (Fox et al., 1976; Weisbroth et al., 1976; Jose, 2011; Adak et al., 2013), Chinese hamsters (Yoon et al., 2000), dogs (Knostman et al., 2003; Rossi et al., 2010) and humans (Kim et al., 2008; Contractor et al., 2014). In this study, we will report an accessory spleen with its macroscopic and microscopic findings in a dog.

A 7 year-old mixed breed male dog weighing $17.5 \mathrm{~kg}$ was fixed by formalin for use as a model in anatomy hall of the Anatomy department, Veterinary Faculty of Shahid Bahonar University of Kerman, Iran. There was no previous history of abdominal pain or haematologic diseases tic animals (Knostman et al., 2003; Rossi

or other clinical abnormalities before being submitted for fixation. During the abdominal dissection, the gross examination showed a $6.3 \times 3.1 \times 1 \mathrm{~cm}$ mass that was situated on the caudodorsal border of the spleen (Fig. 1A). Its axis was along with the main spleen. The appearance and firm consistency of the mass were similar to those of spleen. There was no connection between the spleen and this mass (Fig. 1B). On the other hand, it was supplied by accessory splenic artery which arose from the splenic artery after giving off the epiploic branch (Fig. 2).

For histopathological evaluation, $1 \times 1 \times 1 \mathrm{~cm}$ pieces of three different parts (cranial, middle and caudal) of the mass were taken, washed with PBS (pH 7) and placed in $10 \%$ buffered neutral formaldehyde solution ( $\mathrm{pH}$ 7.2). After 10 days, samples to be embedded in paraffin were fixed in $10 \%$ neutral buffered formalin solution and dehydrated in graded ethanol and xylol alcohols. Five-micrometre sections were stained with haematoxylineosin and assessed using a light microscope.

Microscopic examinations of the mass

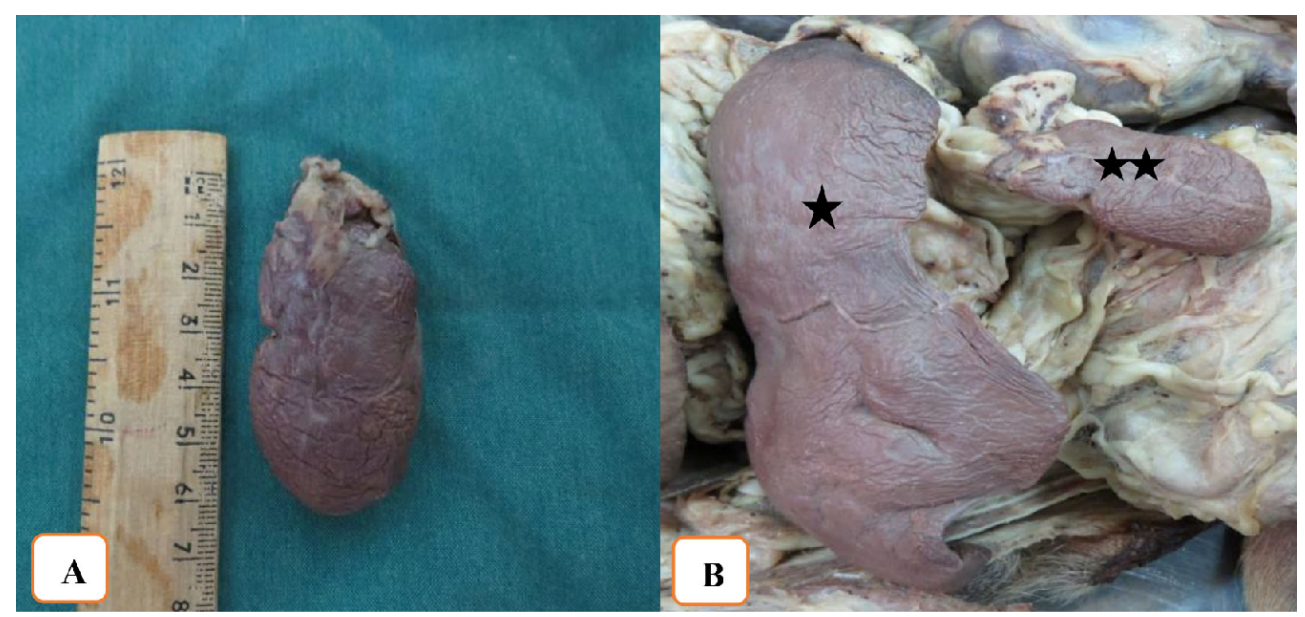

Fig. 1. A. Accessory spleen shape and dimensions;

B. Relation between spleen $(\star)$ and accessory spleen $(\star \star)$. 


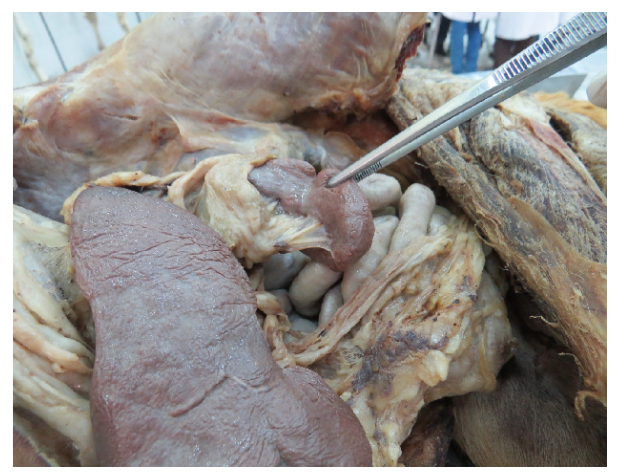

Fig. 2. Spleen hillus and its vessels.

revealed some structures similar to those of spleen. The presence of thick trabeculae was one significant diagnostic point consistent with spleen histology. Also white pulp consisted of depleted splenic lymphatic nodules (Fig. 3). Red pulp was disorganised and some discrete dilated vessels-like structures were observed in the parenchyma (Fig. 4).

Heterotopic splenic tissue can be categorised into two types, splenosis and ac- cessory spleen (De Vuysere et al., 2000; Knostman et al., 2003; Park et al., 2011; Jang et al., 2013). Splenosis occurs when the splenic tissue is autotransplanted through surgical intervention or traumatic splenic rupture. Accessory spleen is a congenital duplicated splenic tissue in a heterotropic location. Reportedly, $80 \%$ of accessory spleens are located around the splenic hilum, although they could be located anywhere in the intraperitoneal cavity from the diaphragm to the pelvis. They occur superficially in the gastrosplenic or splenorenal ligaments, in the mesentery, or even in the pelvis or scrotum (De Vuysere et al., 2000; Park et al., 2011; Jang et al., 2013).

Embryologically, the spleen is a solid organ derived from the mesoderm and has been known to have a less frequency rate of cystic disease than other organs (Fulber et al., 2017). Spleen is formed by fusion of separate masses originating from the left side of the dorsal mesogastrium. Apparently, failure of fusion of these masses

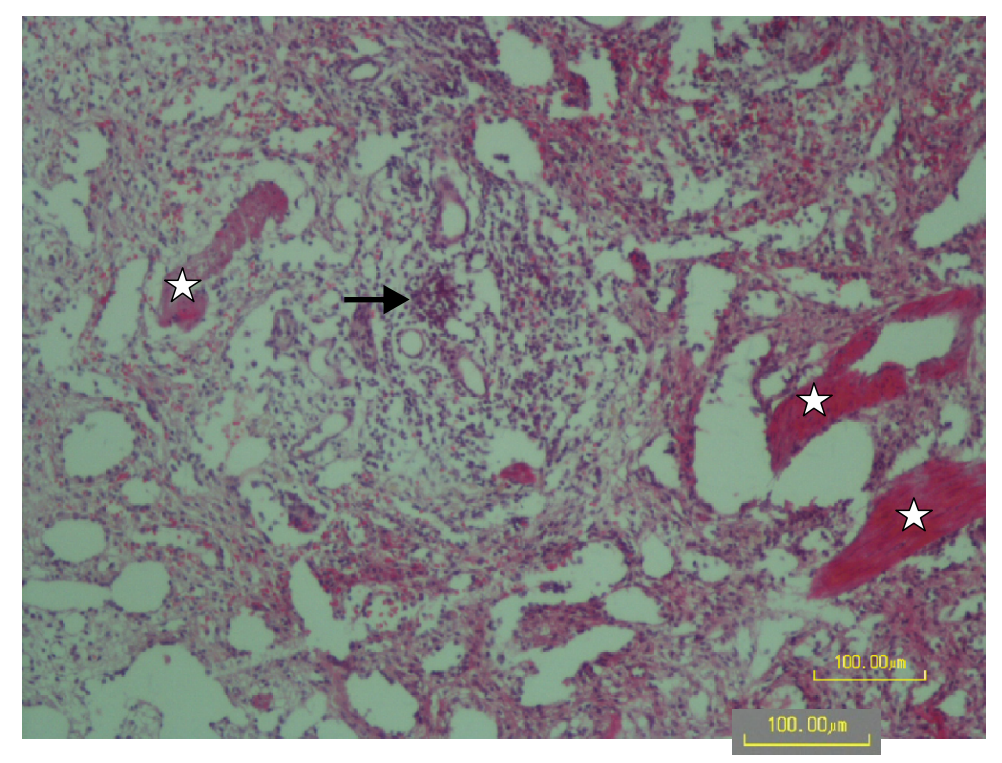

Fig. 3. Histopathologic micrograph of the middle part of the accessory spleen. Thick trabeculae $(\star)$ and depleted follicles (arrow) are visible $(\mathrm{H} \& \mathrm{E} ;$ bar $=100 \mu \mathrm{m})$. 


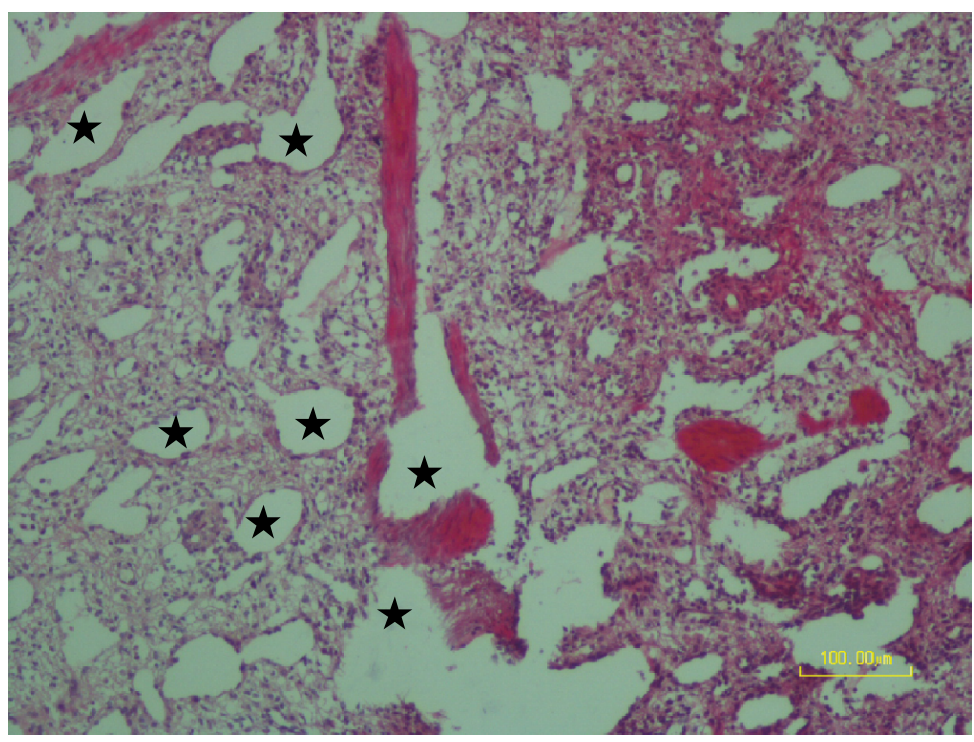

Fig. 4. Disorganised red pulp and a lot of dilated vessels-like structures $(\star)$ are visible in the parenchyma of the cranial part of the accessory spleen. $(\mathrm{H} \& \mathrm{E}$, bar $=100 \mu \mathrm{m})$.

results in the formation of solitary or multiple accessory spleens. Developmentally, the spleen derives its blood supply from the splenic artery; the accessory spleen, when present, generally carries with it a branch of the splenic artery and it drains into the splenic vein. The morphologic structure and the function of the accessory spleen are identical to the main organ (Knostman et al., 2003; Yong et al., 2012).

In the rabbit, Fox et al. (1976) mentioned that accessory spleens are presented adjacent to the splenic hilus, the gastrosplenic ligament and the tail of the pancreas. However, Isegawa et al. (1984) in golden hamsters and Yoon et al. (2000) in Chinese hamsters stated that the accessory spleens were embedded in the adipose tissues near the tail of the pancreas, while, in the chicken the accessory spleen was located cranial, adjacent and caudal to the spleen (Glick \& Sato, 1964). However, in domestic animals Jubb et al. (1993) stated that more accessory spleens were present on the omentum with a few on the peritoneum. It is similar to our case. Two studies, in Baladi goat (Mohamed, 2014) and in Chinese hamsters (Yoon et al., 2000) affirmed that the accessory spleen was morphologically similar to the spleen. Our finding was similar to their reports, while Jubb et al. (1993) reported that in domestic animals the accessory spleens appeared grossly like hemal lymph nodes.

As mentioned before, the accessory spleen is caused by the failure of splenic anlage to fuse during embryogenesis. The size varies from a few millimeters up to 1.5 to $2 \mathrm{~cm}$ in diameter, but in patients with pathologic splenic findings or in those who have previously undergone splenectomy, accessory spleens can hypertrophy and reach a size of $5 \mathrm{~cm}$ or more in humans. In our case, the finding's size was noticeable but there was no abnormal symptom. 
The vascular pedicle of an accessory spleen is most commonly related to the splenic hilum but may also be related to the tail of the pancreas, the gastrosplenic ligament, the small bowel mesentery or to vessels from the fundus of the stomach (Santos et al., 2017). The current study showed that an accessory splenic artery arose from the splenic artery after giving off the epiploic branch to supply the accessory spleen. In contrast, Padmalatha et al. (2010) in human reported that the accessory splenic artery arises from the left gastroepiploic artery.

\section{ACKNOWLEDGEMENTS}

The authors are grateful to Mr. M. Hassanzadeh and Mr. M. Mazhab Jaafari from the Department of Basic Sciences of the Faculty of Veterinary Medicine, Kerman University, Kerman, Iran for their technical assistance.

\section{REFERENCES}

Adak, A., M. C. Prasad, P. S. Lonkar, U. M. Kapurkar, M. G. Brahmankar \& M. V. Patel, 2013. Ectopic spleen in the pancreas of New Zealand White rabbits. Veterinary World, 6, 360-362.

Contractor, U., I. Henderson \& A. Zaitoun, 2014. Intrapancreatic accessory spleen: An important differential to consider before surgery. Human Pathology, 1, 49-51.

De Vuysere, S., W. Van Steenbergen, R. Aerts, H. Van Hauwaert, D. Van Beckenvoort \& L. Van Hoe, 2000. Intrahepatic splenosis: Imaging features. $A b$ dominal Imaging, 25, 187-189.

Fontan, F. J. P., R. Soler, M. Santos \& I. Facio, 2001. Accessory spleen torsion: US, $\mathrm{CT}$ and MRI findings. European Radiology, 11, 509-512.

Fox, R. R., S. H. Weisbroth, D. D. Crary \& S. Scher, 1976. Accessory spleens in domes- tic rabbits. I. Frequency, description and genetic factors. Teratology, 3, 243-252.

Freeman, J. L., S. Z. Jafri, J. L. Roberts, D. G. Mezwa \& A. Shirkhoda, 1993. CT of congenital and acquired abnormalities of the spleen. Radiographics, 13, 597-610.

Fulber, I., C. Wurster, D. Librizzi, M. Röbler, E. Gallmeier, D. K. Bartsch, 2016. Intrapancreatic accessory spleen: a diferential diagnosis to neuroendocrine tumors of the pancreas on Ga-68- DOTATOC PET/TC. Journal of The Pancreas, 17, 427-430.

Glick, B. \& K. Sato, 1964. Accessory spleens in the chicken. Poultry Science, 43, 1610 1612.

Isegawa, N., K. Doi, T. Yamamoto, M. Kataoka \& T. Mizutani, 1984. Morphology of pancreatic tissue-containing accessory spleen in an APA hamster. Experimental Animals, 33, 217-222.

Jang, K. M., S. H. Kim, S. J. Lee, M. J. Park, M. H. Lee, \& D. Choi, 2013. Differentiation of an intrapancreatic accessory spleen from a small $(<3-\mathrm{cm})$ solid pancreatic tumor: Value of diffusion-weighted MR imaging. Radiology, 266, 159-167.

Jose, J., 2011. Ectopic spleen in the pancreas of a New Zealand white rabbit TOXPATH: The Official Newsletter of STP-1, 4, 3-4; http://www.toxpathindia. com/docs/stpi_newsletter_volume4.pdf.

Jubb, K. V. F., P. C. Kennedy \& N. Palmer, 1993. The Pancreas. In: Pathology of domestic animals. $4^{\text {th }}$ edn, vol. 2, W. B. Saunders Ltd, New York, pp. 618-621.

Kim, S. H., J. M. Lee, J. K. Han, J. Y. Lee, K. W. Kim, K. C. Cho \& B. I. Choi, 2008. Intrapancreatic accessory spleen: Findings on MR imaging, CT, US and scintigraphy, and the pathologic analysis. Korean Journal of Radiology, 9, 162-174.

Knostman, K. A., S. E. Weisbrode, P. A. Marrie, \& J. L. Worman, 2003. Intrahepatic splenosis in a dog. Veterinary Pathology, 40, 708-710.

Kurmann, A., J. M. Michel, E. Stauffer \& B. Egger, 2010. Intrapancreatic accessory 
spleen misdiagnosed as a nonsecreting endocrine tumor: Case report and review of the literature. Case Reports in Gastroenterology, 4, 210-214.

Lauder, I., 1992. The spleen. In: Thymus, Lymph Nodes, Spleen and Lymphatics, Systemic Pathology, $3^{\text {rd }}$ ed, eds K. Henry \& W. Symmer, New York, pp. 545-609.

Lehtinen, S. J., C. M. Schammel, M. Devane \& S. D. Trocha, 2013. Intrapancreatic accessory spleen presenting as a pancreatic mass. Journal of Gastrointestinal Onco$\log y, 4,23-26$.

Mohamed, R. A., 2014. Double spleen in Baladi goat in Beni-Suef governorate. Iraqi Journal of Veterinary Sciences, 28, 105-107.

Padmalatha, K., R. Ramesh, B. S. Prakash, N. Balachandra \& Y. Mamatha, 2010. Accessory splenic artery from left gastroepiploic artery. International Journal of Anatomy and Variation, 3, 106-107.

Park, Js., W. J. Kim, Y. G. Jeong, Y. S. Park, H. C. Koo, T. I. Lee, G. C. Choi, \& S. Kim, 2011. A case of intrapancreatic accessory spleen mistaken as a pancreatic mass due to different enhancing pattern from normal spleen. The Korean Society of Gastroenterology, 58, 357-360.

Rossi, F., S. Rabba, M. Vignoli, H. Haers, R. Terragni, \& J. H. Saunders, 2010. B-mode and contrast-enhanced sonographic assessment of accessory spleen in the dog. Veterinary Radiology and Ultrasound, 51, 173-177.

Santos, M. P., A. P. Rezende, P. V. S. Filho, J. E. Gonçalves, F. B. Beraldo, \& A. P. Sampaio, 2017. Intrapancreatic accessory spleen. Einstein, 15, 366-368.

Swarbrick, O., 1968. Ectopic splenic nodules in the pancreas of a sow. British Veterinary Journal, 124, 6-18.

Tatekawa, Y., 2018. An intrapancreatic accessory spleen presenting as a rapidly growing pancreatic mass after splenectomy in a patient with hereditary spherocytosis: A case report and literature review. Journal of Surgical Case Reports, 2, 1-3.
Weisbroth, S. H., R. R. Fox, S. Scher \& D. D. Cray, 1976. Accessory spleens in domestic rabbits (Oryctolagus suniculus). II. Increased frequency in hematological diseases and experimental induction with phenylhydrazine. Teratology, 13, 253262.

Yong, J. K., P. K. Hwon, \& K. G. Lee, 2012, Misdiagnosis of intrapancreatic accessory spleen as an endocrine tumor of the pancreatic tail. Clinical Gastroenterology and Hepatology, 10, 28-29.

Yoon, Y., J. Shin, C. Park, Y. Oh, I. Lee, H. Lee \& J. Lee, 2000. Morphological structure of accessory spleen in Chinese hamsters. Journal of Veterinary Science, 1, 73-75.

Paper received 05.03.2019; accepted for publication 03.08.2019

\section{Correspondence:}

Mohammad Naser Nazem Department of Basic Sciences, School of Veterinary Medicine, Shahid Bahonar University of Kerman, P.O Box: 7616914111, Kerman, Iran, tel: +983431322954 , fax: +983433257250 , e-mail: nnazem@uk.ac.ir; nasernazem@yahoo.com 